\title{
Correction to: A low delay rate control method for screen content coding
}

\author{
Tong Tang ${ }^{1} \cdot$ Ling $\mathrm{Li}^{2,3}$ \\ Published online: 24 July 2020 \\ (C) Springer Science+Business Media, LLC, part of Springer Nature 2019
}

Correction to: Multimedia Tools and Application (2019) 78:28231-28256

https://doi.org/10.1007/s11042-019-07910-9

In the original publication, the corresponding author's affiliation was incorrect. The correct affiliation is presented in this erratum. The author regrets this mistake.

The online version of the original article can be found at https://doi.org/10.1007/s11042-019-07910-9

Tong Tang

ttly@mail.ustc.edu.cn

Ling Li

liling@iscas.ac.cn

1 School of Communication and Information Engineering, Chongqing University of Posts and Telecommunications, Chongqing, China

2 Institute of Software, Chinese Academy of Sciences, Beijing, China

3 University of Chinese Academy of Sciences, Beijing, China 